\title{
Diagnostic value of the gynecology imaging reporting and data system (Gl- RADS) with the ovarian malignancy marker CA-125 in preoperative adnexal tumor assessment
}

\author{
Michal Migda ${ }^{1,3^{*}}$, Migda Bartosz ${ }^{2}$, Marian S. Migda ${ }^{3}$, Marcin Kierszk ${ }^{1}$, Gieryn Katarzyna ${ }^{1}$ and Marek Maleńczyk ${ }^{1}$
}

\begin{abstract}
Objectives: The purpose of this study is to assess the preoperative evaluation of an adnexal mass using the GIRADS classification and to verify whether CA-125 measurement can offer any additional benefits to the GI-RADSbased prediction of ovarian tumor malignancy.

Material and methods: In this study, we assessed a total of 215 women with an adnexal tumor using the GI-RADS classification combined with CA-125 measurement. All adnexal masses underwent histological verification.

Results: Of a total of 215 lesions, we classified 2 lesions as GI-RADS 2 (0.9\%), 118 lesions as GI-RADS 3 (54.9\%), 86 lesions as GI-RADS 4 (40.0\%) and 9 lesions as GI-RADS 5 (4.2\%). For GI-RADS $4-5$ lesions, the sensitivity, specificity, PPV, NPV, ACC and OR were as follows: 94.3, 72.2, 52.6, 97.5, 77.7\%, and 43.3 (Cl 12.0-146), respectively. The corresponding parameters resulting from combining the GI-RADS classification with the CA-125 marker were as follows: 66.0, 93.8, 77.8, 89.4, 87.0\%, and 29.6 (Cl 12.6-69.6), respectively, with $p<0.001$. For Ca-125 $>30 \mathrm{IU} / \mathrm{mL}$ alone, the results were as follows: 70.0, 80.3, 53.8, 89.1, 77.7\%, and 9.5 (4.6-19.6), respectively, with $p<0.0001$.

Additionally, $47.8 \%$ of the patients had no symptoms, $36.5 \%$ had back pain, $5.2 \%$ had an increased abdominal size, $4.3 \%$ had menstrual irregularities and $2.6 \%$ had constipation. There were 152 benign and 18 malignant cases in the low risk group (GIRADS $1-3$ and GIRADS $4+C A-125<30 \mathrm{IU} / \mathrm{mL}$ ) and 10 benign and 35 malignant tumors in the high-risk group (GIRADS $4+$ CA125 $>30 \mathrm{IU} / \mathrm{mL}$ and GIRADS 5).
\end{abstract}

Conclusions: GI-RADS classification had good performance in discriminating ovarian tumors. The additional measurement of CA-125 improves the system specificity, PPV and ACC for preoperative adnexal tumor assessment.

Keywords: Gynecology imaging reporting and data system, Ca-125, Ultrasound, Ovarian tumor

\section{Introduction}

Ovarian cancer is the most lethal cancer among gynecological malignancies. It has been estimated that over 151,000 women died from this disease in 2012 worldwide [1]. In Poland, ovarian cancer is the second most frequently diagnosed malignancy of the female

\footnotetext{
*Correspondence: mchmigda@gmail.com

${ }^{1}$ Clinical Unit of Obstetrics, Women's Disease and Gynecological Oncology, sw. Jozefa 53/59, United District Hospital, Collegium Medicum University of Nicolaus Copernicus in Toruń, Torun, Poland

${ }^{3}$ Civis Vita Medical Center, Torun, Poland

Full list of author information is available at the end of the article
}

genital tract, with an incidence rate of 3600 new cases per year, and has the highest mortality among gynecological cancers, reaching 2600 deaths every year [2]. Sadly, nearly $70 \%$ of patients with ovarian cancer are diagnosed at an advanced stage, while the 5-year survival rate for patients with ovarian cancer may be as high as $90 \%$ when treated early [3]. It has been demonstrated that the survival of ovarian cancer patients is better when treatment is provided at specialized centers by gynecologists with expertise in gynecologic oncology [4]. To date, surgical treatment, chemotherapy, radiotherapy,

(c) The Author(s). 2018 Open Access This article is distributed under the terms of the Creative Commons Attribution 4.0 International License (http://creativecommons.org/licenses/by/4.0/), which permits unrestricted use, distribution, and 
biotargeted therapy and other technologies have improved. Screening tumor markers using gene chip technology by detecting the hypomethylation of certain genes may be potentially helpful in high-risk groups, such as BRCA1 and BRCA2 patients, but not in the general population [5]. Studies based on proteomics are based on appropriate protein analysis technology such as surface-enhanced laser desorption/ionization time-offlight (TOF)-MS, which shows $100 \%$ sensitivity and 93.3\% specificity, indicating that this approach is useful for diagnosing ovarian cancer [6]. A cytogenetic analysis study by Lagana showed that the progression of epithelial ovarian cancer is characterized by a series of combined epigenetic aberrations determined by loss of methylation of certain regions of DNA encoding genes such as the Ras-association domain-containing family 1 (RASSF1A) tumor suppressor, which is considered a new diagnostic development [7]. Additionally, technical improvement allows surgery on a patient with an early stage of ovarian carcinoma using laparoscopy or robot-assisted laparoscopy, making this an acceptable approach for this selected group [8]. The preoperative assessment of an adnexal mass is difficult, which leads to a disproportionate number of women with benign ovarian tumors being referred to specialized centers and, conversely, women with ovarian malignancy being inappropriately operated on in nonspecialized centers [4]. Ultrasonography is currently considered the primary imaging modality for identifying and characterizing adnexal masses [9]. Due to the subjective nature of the examination, there has been a need for standardized nomenclature and a definition of all tumor features evaluated by ultrasound. The International Ovarian Tumor Analysis provides consensus on ultrasonography nomenclature and definitions of all tumor features and has improved the discrimination of adnexal masses by including a quantitative assessment of some morphological features [10]. In 2009, based on the Breast Imaging Reporting and Data System (BI-RADS), Amor et al. proposed a Gynecology Imaging Reporting and Data System (GI-RADS) as a similar system to facilitate communication between sonographers and referring clinicians [11]. The contemporary diagnostic standard for ovarian cancer includes transvaginal ultrasound and the measurement of serum CA-125. A wide range of other diagnostic approaches is being investigated at present [1].

The purpose of this study was to assess the performance of the GI-RADS reporting system in the preoperative discrimination of adnexal masses in Polish women and to test whether the measurement of CA-125 can offer any additional benefits to the GI-RADS risk evaluation for the malignancy of ovarian tumors.

\section{Materials and methods}

This study was approved by the board of Clinical Unit of Obstetrics, Women's Disease and Gynecological Oncology, United District Hospital, Collegium Medicum University of Nicolaus Copernicus in Torun, Poland. Over a 24-month period, we enrolled a total of 215 women with adnexal masses into the study. The inclusion criteria were primarily based on the clinical diagnosis of an adnexal mass followed by ultrasound confirmation at our tertiary center and the obtaining data indicating pathology. Patients with pregnancy, bilateral adnexal tumors or a malignancy diagnosis already established were excluded from the study.

Patients were assessed by an experienced examiner (500 scans a year) 2-3 days prior to surgery. Vaginal and transabdominal two-dimensional (2D) ultrasound examinations were performed using a Voluson E8 (GE Medical Systems, Zipf, Austria). Morphological features were examined according to GI-RADS and included unilateral involvement, the maximum diameter of the lesion, the wall thickness, septa, solid papillary projections, solid areas within the cyst, cystic content and ascites [6]. Color Doppler was used to assess peripheral or central vascularization.

Peripheral blood was collected for the measurement of serum CA-125 1 to 14 days prior to surgery. Blood was collected from all patients and stored in serum separator tubes. Automated analysis of CA-125 was performed by direct chemiluminescence using an Advia Centaur CA-125 II assay (Siemens Medical Solutions Diagnostics, Tarrytown, USA). Values were expressed in international units per milliliter $(\mathrm{IU} / \mathrm{mL})$.

A definitive histological diagnosis was obtained from surgical excision or a biopsy sample. Tumors were classified according to the WHO criteria [8]. Borderline tumors were considered malignant for the purposes of the present study. Statistical analysis was performed using the statistical software STATISTICA 10 (StatSoft Inc.). GI-RADS classification was combined with a CA-125 assay, and descriptive measures were calculated (for CA-125 > $30 \mathrm{IU} / \mathrm{mL}$ ): sensitivity, specificity, positive predictive value (PPV), negative predictive value (NPV), accuracy (ACC), and odds ratio (OR) at a 95\% confidence interval. In all cases of a categorical variable comparison, a Chi-squared test was used. In the case of GI-RADS, categories 2 and 3 were considered low-risk, while categories 4 and 5 were considered high-risk. Histological diagnosis was used as a gold standard. Continuous variables, such as age, were assessed using a Mann-Whitney $\mathrm{U}$ test. For all analyses, $p<0.05$ was considered significant.

\section{Results}

The study was based on the analysis of 215 unilateral adnexal tumors. The average age of the patients was 
47.2 years old (range $=13-89$ ). The average age of the patients in the malignant tumor group was significantly higher than that in the benign tumor group: 60 years (range 36-89) vs 43.1 years (range 13-84), respectively, with a $p$-value of $<0.001$ for both groups. We found a total of 53 masses to be malignant (24.7\% of all adnexal tumors). In the 215 tumors, 2 lesions were classified as GI-RADS 2 (0.9\%), 118 lesions were GI-RADS 3 (54.9\%), 86 lesions were GI-RADS $4(40.0 \%)$ and 9 lesions were GI-RADS 5 (4.2\%). Table 1 shows all GI-RADS categories with the corresponding histological results. According to the GI-RADS classification, we had 2 cases of ovarian cancer that were classified in the low-risk category 3 (Table 1), of which one was in an asymptomatic 80-year-old woman and the other was in a 42-year-old woman with menstrual irregularities.

For GI-RADS classifications 4 and 5, the sensitivity, specificity, PPV, NPV, ACC and OR values were as follows: $94.3,72.2,52.6,97.5,77.7 \%$ and 43.3 , respectively (CI 12.0-146). For the GI-RADS classification combined with the CA-125 marker, the sensitivity, specificity, PPV, NPV, ACC and OR values were as follows: 66.0, 93.8, $77.8,89.4,87.0 \%$ and 29.6 , respectively (CI 12.6-69.6, $p<0.001)$. For $\mathrm{Ca}-125>30 \mathrm{IU} / \mathrm{mL}$ alone, the sensitivity, specificity, PPV, NPV, ACC and OR values were as follows: $70.0,80.3,53.8,89.1,77.7 \%$ and 9.5 , respectively (CI 4.6-19.6, $p<0.0001$ ) (Table 2).

GI-RADS classification had the highest sensitivity of all methods used. The application of Ca-125 measurement as

Table 1 GI-RADS classification according to specific histopathologic diagnoses

\begin{tabular}{|c|c|c|c|c|c|c|c|c|}
\hline \multirow[t]{2}{*}{ Histopathology } & \multicolumn{4}{|c|}{ GI-RADS } & \multirow[t]{2}{*}{$\mathrm{N}$} & \multirow[t]{2}{*}{$\%$} & \multirow{2}{*}{$\begin{array}{l}\% \text { of } \\
\text { malignant }\end{array}$} & \multirow{2}{*}{$\begin{array}{l}\% \\
\text { benign }\end{array}$} \\
\hline & 2 & 3 & 4 & 5 & & & & \\
\hline adenocarcinoma ovary & 0 & 2 & 36 & 6 & 44 & $20.5 \%$ & $83.0 \%$ & \\
\hline carcinoma papillare & 0 & 0 & 0 & 1 & 1 & $0.5 \%$ & $1.9 \%$ & \\
\hline cystadenofibroma serosum proliferans & 0 & 0 & 1 & 1 & 2 & $0.9 \%$ & $3.8 \%$ & \\
\hline cystadenoma mucinosum proliferans & 0 & 0 & 1 & 0 & 1 & $0.5 \%$ & $1.9 \%$ & \\
\hline cystadenoma proliferans & 0 & 1 & 3 & 1 & 5 & $2.3 \%$ & $9.4 \%$ & \\
\hline corpus luteum & 1 & 1 & 0 & 0 & 2 & $0.9 \%$ & & $1.2 \%$ \\
\hline corpus luteum hemorrhagicum & 0 & 1 & 1 & 0 & 2 & $0.9 \%$ & & $1.2 \%$ \\
\hline cystadenofibroma & 1 & 1 & 5 & 0 & 7 & $3.3 \%$ & & $4.3 \%$ \\
\hline cystadenofibroma mucinosum & 0 & 1 & 2 & 0 & 3 & $1.4 \%$ & & $1.9 \%$ \\
\hline cystadenofibroma serosum & 0 & 4 & 2 & 0 & 6 & $2.8 \%$ & & $3.7 \%$ \\
\hline cystadenoma mucinosum & 0 & 4 & 1 & 0 & 5 & $2.3 \%$ & & $3.1 \%$ \\
\hline cystadenoma serosum & 0 & 2 & 0 & 0 & 2 & $0.9 \%$ & & $1.2 \%$ \\
\hline cystis benigna & 0 & 0 & 1 & 0 & 1 & $0.5 \%$ & & $0.6 \%$ \\
\hline cystis follicularis & 0 & 2 & 1 & 0 & 3 & $1.4 \%$ & & $1.9 \%$ \\
\hline cystis lueinisans & 0 & 2 & 0 & 0 & 2 & $0.9 \%$ & & $1.2 \%$ \\
\hline cystis serosa & 0 & 16 & 6 & 0 & 22 & $10.2 \%$ & & $13.6 \%$ \\
\hline cystis serosa paraovarialis & 0 & 11 & 0 & 0 & 11 & $5.1 \%$ & & $6.8 \%$ \\
\hline cystis serosa paraoviducti & 0 & 1 & 0 & 0 & 1 & $0.5 \%$ & & $0.6 \%$ \\
\hline cystis serosum & 0 & 1 & 0 & 0 & 1 & $05 \%$ & & $0.6 \%$ \\
\hline cystis simplex & 0 & 3 & 0 & 0 & 3 & $1.4 \%$ & & $1.9 \%$ \\
\hline dermoidalna & 0 & 2 & 0 & 0 & 2 & $0.9 \%$ & & $1.2 \%$ \\
\hline endometrioma & 0 & 35 & 7 & 0 & 42 & $19.5 \%$ & & $25.9 \%$ \\
\hline fibrothecoma & 0 & 1 & 6 & 0 & 7 & $3.3 \%$ & & $4.3 \%$ \\
\hline folliculoma & 0 & 0 & 2 & 0 & 2 & $0.9 \%$ & & $1.2 \%$ \\
\hline hydrosalpinx & 0 & 1 & 1 & 0 & 2 & $0.9 \%$ & & $1.2 \%$ \\
\hline myoma pedunculated & 0 & 1 & 0 & 0 & 1 & $0.5 \%$ & & $0.6 \%$ \\
\hline ovarian abscess & 0 & 0 & 1 & 0 & 1 & $0.5 \%$ & & $0.6 \%$ \\
\hline teratoma & 0 & 25 & 9 & 0 & 34 & $15.8 \%$ & & $21.0 \%$ \\
\hline All & 2 & 118 & 86 & 9 & 215 & $100.0 \%$ & $100.0 \%$ & $100.0 \%$ \\
\hline
\end{tabular}

$N$ - number of cases 
Table 2 Statistical analysis of GI-RADS classification and levels of the ovarian malignancy marker CA-125

\begin{tabular}{|c|c|c|c|c|c|c|c|c|}
\hline Descriptive Statistics & Sensitivity & Specificity & PPV & NPV & ACC & OR & OR 95\% Cl & $p$-value \\
\hline Gl-RADS + CA $125>30 \mathrm{IU} / \mathrm{mL}$ & $66.0 \%$ & $93.8 \%$ & $77.8 \%$ & $89.4 \%$ & $87.0 \%$ & 29.6 & $12.6-69.6$ & $<0.00001$ \\
\hline GI-RADS 4-5 & $94.3 \%$ & $72.2 \%$ & $52.6 \%$ & $97.5 \%$ & $77.7 \%$ & 43.3 & $12.9-14.6$ & $<0.0000$ \\
\hline $\mathrm{CA}-125>30 \mathrm{IU} / \mathrm{mL}$ & $70.0 \%$ & $80.3 \%$ & $53.8 \%$ & $89.1 \%$ & $77.7 \%$ & 9.5 & $4.6-19.6$ & $<0.0000$ \\
\hline
\end{tabular}

$\mathrm{IU} / \mathrm{m} /$ international units per milliliter, $A C C$ accuracy, $P P V$ positive predictive value, NPV negative predictive value, $O R$ odds ratio, $C I$ confidence interval

an additional differentiation criterion improved the specificity of GI-RADS: $93.8 \%$ (with CA-125) vs $72.2 \%$ (without). Other descriptive statistics also seemed to have improved as well: a PPV of $77.8 \%$ vs $52.6 \%$ and an accuracy of $87 \%$ vs $77.7 \%$ with and without Ca-125, respectively. Unfortunately, the odds ratio decreased by approximately $30 \%$, from 43.3 to 29.6 . However, the odds ratio was still considerably higher for the combined measure than for Ca-125 alone: 29.6 vs 9.5 .

The percentage of malignant tumors in our study was quite high (24.7\%). The most frequent histological manifestation was adenocarcinoma (44 cases), which constituted approximately $83 \%$ of all the malignant cases. There were two malignant tumors classified as GI-RADS 3 ("probably benign"), which comprised 3.77\% of all malignant cases. We classified a total of 42 lesions as "probably malignant" or "very probably malignant", which corresponded to 36 cases of GI-RADS 4 (85.7\%) and 6 cases of GI-RADS 5 (13.6\%), respectively. Among the malignant ovarian tumors, we diagnosed 9 cases $(20.5 \%$ of the malignant cases, and $3.7 \%$ of the adnexal masses).

Regarding symptoms, $47.8 \%$ of patients were symptom-free and the rest had back pain (36.5\%), increased abdominal size (5.2\%), menstrual irregularities (4.3\%) and constipation (2.6\%) (Table 3). In the low-risk group (GIRADS $1-3$ and GIRADS 4 with CA-125 $<30 \mathrm{IU} / \mathrm{mL}$ ),

Table 3 Clinical symptoms of women with adnexal masses

\begin{tabular}{|c|c|c|c|c|c|c|}
\hline \multirow[t]{2}{*}{ Clinical symptoms } & \multicolumn{4}{|c|}{ Gl-RADS } & \multirow[t]{2}{*}{ N } & \multirow[t]{2}{*}{$\%$} \\
\hline & 2 & 3 & 4 & 5 & & \\
\hline Lack of symptoms & 1 & 64 & 44 & 1 & 110 & $47.8 \%$ \\
\hline Back pain & 1 & 50 & 32 & 1 & 84 & $36.5 \%$ \\
\hline Increased abdomen size & 1 & 0 & 6 & 5 & 12 & $5.2 \%$ \\
\hline Menstrual irregularities ${ }^{a}$ & 0 & 3 & 5 & 2 & 10 & $4.3 \%$ \\
\hline Constipation & 0 & 2 & 3 & 1 & 6 & $2.6 \%$ \\
\hline Weight loss & 0 & 0 & 2 & 0 & 2 & $0.9 \%$ \\
\hline Pain during intercourse ${ }^{b}$ & 0 & 2 & 0 & 0 & 2 & $0.9 \%$ \\
\hline Nausea & 0 & 1 & 0 & 0 & 1 & $0.4 \%$ \\
\hline Leg swelling & 0 & 0 & 1 & 0 & 1 & $0.4 \%$ \\
\hline Frequent urination & 0 & 0 & 1 & 0 & 1 & $0.4 \%$ \\
\hline Urinary retention & 0 & 0 & 1 & 0 & 1 & $0.4 \%$ \\
\hline All & 3 & 122 & 95 & 10 & 230 & $100.0 \%$ \\
\hline
\end{tabular}

${ }^{a}$ only for premenopausal women, ${ }^{b}$ for sexually active women; $N$ - number of cases we report 152 benign and 18 malignant cases. In the high-risk group (GIRADS 4 with CA-125 > $30 \mathrm{IU} / \mathrm{mL}$ and GIRADS 5), we report 10 benign and 35 malignant tumors (Table 4).

\section{Discussion}

We found that using GI-RADS classification is not an effective method for predicting the malignancy of ovarian tumors when combined with CA-125 level measurement. When the GI-RADS system is combined with CA-125 levels of $>30 \mathrm{IU} / \mathrm{ml}$, we report low sensitivity and high specificity for malignancy discrimination (66.0 and $93.8 \%$, respectively). We also found that for GI-RADS 4 and 5, GI-RADS had higher sensitivity but lower specificity than for lower GI-RADS classifications: 94.3 and $72.2 \%$, respectively. The results regarding GI-RADS performance are similar to those published by Zhang et al., despite the fact that the authors did not analyze the CA-125 levels as an additional marker for malignancy discrimination [12]. Following Amor et al., we support the statement that the GI-RADS classification system is useful for clinical decision-making and patient management $[11,13]$. Due to the progress in the image quality and resolution of transvaginal ultrasound, image scores improve the objectivity and accuracy of ovarian tumor diagnosis [13]. Furthermore, ovarian tumor morphology assessment is subjective and requires the training and experience of sonographers to maintain a high quality of performance [14]. GI-RADS classification was developed in 2009 to simplify communication between sonographers and clinicians/gynecologists [11]. It is suggested that GI-RADS 4 and 5 cases be referred to a gynecological oncologist due to the $20 \%$ risk of malignancy [13]. Moszynski et al. highlight that the GI-RADS classification is a subjective measure, especially in the case of tumors classified as GI-RADS 4, which are considered to be difficult to assess [14]. Although there are other methods and scoring systems

Table 4 Diagnostic performance of GI-RADS classification with CA-125

\begin{tabular}{|c|c|c|}
\hline GI-RADS & Benign & Malignant \\
\hline GI-RADS $1-3$ and GI-RADS $4+$ CA-125 $<30 \mathrm{IU} / \mathrm{mL}$ & 152 & 18 \\
\hline GI-RADS $4+$ CA-125 > 30 IU/mL and GI-RADS 5 & 10 & 35 \\
\hline All & 162 & 53 \\
\hline
\end{tabular}


to distinguish between malignant and benign ovarian tumors, these methods have complex scoring and regression of ultrasonographic findings and require combining the ultrasonographic results with laboratory indexes $[10,12,15,16]$. More data is needed, however, for GI-RADS classification performance when used by nonexpert examiners.

The assessment of biomarkers may be a more objective method suitable for less-experienced ultrasonographers [14]. CA-125 is the most popular and widely used ovarian cancer marker, but its effectiveness in terms of ovarian cancer differential diagnosis is questionable [1, 4, 17-21]. While CA-125 is quite accurate among postmenopausal women, its many false-positive results in premenopausal patients are a main limitation [22]. Our cutoff value for CA-125 levels was $30 \mathrm{IU} / \mathrm{ml}$, which can explain the low sensitivity (70\%). Niemi et al. report a CA-125 sensitivity of $59.4 \%$ with a cutoff of $35 \mathrm{kU} / \mathrm{ml}$, whereas Wang et al., using the same cutoff value, report a sensitivity and specificity of 85.9 and $85.2 \%$, respectively [18]. The main reason for the late-stage increase in the CA-125 serum concentration could be the molecular weight of the protein, $200-1000 \mathrm{kDa}$, compared to that of human epididymis protein 4 (HE4), which is $25 \mathrm{kDa}$. The other clinical implication is the lack of specificity of CA-125 in patients with endometriosis. Thus, it is easy to misdiagnose ovarian endometriosis as ovarian cancer, which can lead to significant physical and physiological harm inflicted to patients [23]. Koneczny et al. report that the IOTA group LR1 and GI-RADS performed well when used by either experienced or less-experienced operators of ultrasound systems [24]. For prognostic models such as GI-RADS, very high sensitivity (94.6\%) and good specificity (75.5\%) for examiners at level III and level II (72.7 and 87.8\%, respectively) was reported. Nevertheless, in our study, we report that combining GI-RADS with CA-125 measurements can yield improved values for diagnostic parameters such as sensitivity, specificity, PPV, NPV, ACC and OR, which were $66.0,93.8,77.8,89.4,87.0 \%$ and 29.6 , respectively. A study by Lycke et al. reported that in postmenopausal women, RMI (> 200), ROMA (>/=29.9), CA-125 (> 35 U/ $\mathrm{ml})$, and HE4 (>140 pmol/l) showed a sensitivity of 89 , 91,92 , and $72 \%$ and a specificity of $80,77,80$, and $92 \%$, respectively. In premenopausal women, the sensitivity of RMI, ROMA (>/=11.6), CA125, and HE4 (> $70 \mathrm{pmol} / \mathrm{l})$ was $87,87,96$, and $83 \%$, and the specificity was $90,81,60$, and 91\% [25], respectively. These results suggest that CA125 is superior to HE4 as a biomarker to identify women with ovarian cancer. HE4 is better at identifying benign lesions, which may help with differential diagnoses to guide the level of care and decrease overtreatment [25].

In evaluating the symptoms, we noticed that $47.8 \%$ of all cases were actually symptom-free. If present, symptoms were nonspecific, such as back pain (36.5\%), while an increased abdominal size was typical for GI-RADS 4 and 5 cases. Pitta et al. reported good discrimination of tumors based on the Ward agglomerative method for hierarchical clustering using the following symptoms: abdominal bloating and/or increased abdominal size, back pain, leg swelling, eating (unable to eat, feeling full quickly), feeling of abdominal mass, miscellaneous (fatigue and or difficulty breathing), digestion (indigestion and/or nausea/vomiting), bladder (urinary urge and/or frequent urination), and in combination with CA-125, this guidance should facilitate decision making for primary care physicians $[4,26]$. In our opinion, this promising data presented by Pitta et al. enhanced further prospective research.

Our study has some limitations. First, this study was a retrospective study. Second, this study was based on data from only one health center, yielding a rather small cohort and possible examiner bias. Third, in our study, we had 2 ovarian cancers classified as low-risk (GI-RADS 3 ), of which one case was in a symptomless 80 -year-old patient and the other case was in a 42-year-old patient with menstrual irregularities.

In conclusion, the GI-RADS classification showed good performance in discriminating ovarian tumors. GI-RADS is considered a useful tool for the management of patients with an adnexal mass who are referred to a tertiary center. When combined with the measurement of CA-125, the test specificity, PPV and ACC for the assessment of preoperative adnexal tumors is improved. Future studies should seek clinically sensitive imaging diagnostic methods for ovarian pathologies to establish an integrated, relatively specific system for early warning of tumors.

\section{Abbreviations \\ CA-125: cancer antigen 125; GI-RADS: Gynecology imaging reporting and data system}

\section{Acknowledgments}

We thank all of the patients for participating in the study.

\section{Funding \\ None.}

\section{Availability of data and materials}

The datasets used and/or analyzed during the current study are available from the corresponding author upon reasonable request.

\section{Authors' contributions}

MM, Project development, data collection, and manuscript writing; MB, data analysis; MSM, data analysis and manuscript editing; MK, data collection; GK, manuscript editing; and MM, manuscript editing. All authors read and approved the final manuscript.

\section{Ethics approval and consent to participate}

The board of the Clinical Unit of Obstetrics, Women's Disease and Gynecological Oncology, United District Hospital, Collegium Medicum University of Nicolaus Copernicus in Toruń approved the study. Verbal 
informed consent was obtained from all patients, and the study was conducted in accordance with the regulations of our department.

\section{Competing interests}

The authors declare that they have no competing interests.

\section{Publisher's Note}

Springer Nature remains neutral with regard to jurisdictional claims in published maps and institutional affiliations.

\section{Author details}

${ }^{1}$ Clinical Unit of Obstetrics, Women's Disease and Gynecological Oncology, sw. Jozefa 53/59, United District Hospital, Collegium Medicum University of Nicolaus Copernicus in Toruń, Torun, Poland. ${ }^{2}$ Department of Diagnostic Imaging, Second Faculty of Medicine with the English Division and the Physiotherapy Division, Medical University of Warsaw, Warsaw, Poland. ${ }^{3}$ Civis Vita Medical Center, Torun, Poland

\section{Received: 7 May 2018 Accepted: 24 October 2018}

\section{Published online: 03 November 2018}

\section{References}

1. Terlikowska KM, Dobrzycka B, Witkowska AM, Mackowiak-Matejczyk B, Sledziewski TK, Kinalski M, Terlikowski SJ. Preoperative HE4, CA125 and ROMA in the differential diagnosis of benign and malignant adnexal masses. J Ovarian Res. 2016:9(1):43.

2. Reports based on data of National Cancer Registry. The Maria SklodowskaCurie Memorial Cancer Center. Department of Epidemiology and Cancer Prevention NCRAfh. In.; 2013. http://epid.coi.waw.pl/krn. Accessed 23 Mar 2016.

3. Aebi S, Castiglione M, Group EGW. Newly and relapsed epithelial ovarian carcinoma: ESMO clinical recommendations for diagnosis, treatment and follow-up. Ann Oncol. 2009;20(Suppl 4):21-3.

4. Pitta Dda R, Sarian Lo Fau - Barreta A, Barreta A Fau - Campos EA, Campos Ea Fau - Andrade LLdA, Andrade LI Fau - Fachini AMD, Fachini Am Fau Campbell LM, Campbell Lm Fau - Derchain S, Derchain S. Symptoms, CA125 and HE4 for the preoperative prediction of ovarian malignancy in Brazilian women with ovarian masses. BMC Cancer. 2013;18(13):423. https://doi.org/ 10.1186/1471-2407-13-423

5. Dong X, Men X, Zhang W, Lei P. Advances in tumor markers of ovarian cancer for early diagnosis. Indian J Cancer. 2014;51(Suppl 3):e72-6.

6. Zhang WY, Zhu LR, Zheng YH, Zhou L, Zhang JZ, Wu JH, Liao QP. Study for drug-resistance of epithelial ovarian cancer by serum protein profiling. Zhonghua Yi Xue Za Zhi. 2009;89(19):1326-9.

7. Lagana AS, Colonese F, Colonese E, Sofo V, Salmeri FM, Granese R, Chiofalo B, Ciancimino L, Triolo O. Cytogenetic analysis of epithelial ovarian cancer's stem cells: an overview on new diagnostic and therapeutic perspectives. Eur J Gynaecol Oncol. 2015;36(5):495-505.

8. Bellia A, Vitale SG, Lagana AS, Cannone F, Houvenaeghel G, Rua S, Ladaique A, Jauffret C, Ettore G, Lambaudie E. Feasibility and surgical outcomes of conventional and robot-assisted laparoscopy for early-stage ovarian cancer: a retrospective, multicenter analysis. Arch Gynecol Obstet. 2016;294(3):615-22.

9. American College of O, Gynecologists. ACOG practice bulletin. Management of adnexal masses. Obstet Gynecol. 2007;110(1):201-14.

10. Alcazar JL, Pascual MA, Graupera B, Auba M, Errasti T, Olartecoechea B, RuizZambrana A, Hereter L, Ajossa S, Guerriero S. External validation of IOTA simple descriptors and simple rules for classifying adnexal masses. Ultrasound Obstet Gynecol. 2016;48(3):397-402.

11. Amor F, Vaccaro H, Alcazar JL, Leon M, Craig JM, Martinez J. Gynecologic imaging reporting and data system: a new proposal for classifying adnexal masses on the basis of sonographic findings. J Ultrasound Med. 2009;28(3):285-91.

12. Zhang T, Li F, Liu J, Zhang S. Diagnostic performance of the gynecology imaging reporting and data system for malignant adnexal masses. Int J Gynaecol Obstet. 2017;137(3):325-31.

13. Amor F, Alcazar JL, Vaccaro H, Leon M, Iturra A. GI-RADS reporting system for ultrasound evaluation of adnexal masses in clinical practice: a prospective multicenter study. Ultrasound Obstet Gynecol. 2011;38(4):450-5.

14. Moszynski R, Szubert S, Szpurek D, Michalak S, Sajdak S. Role of osteopontin in differential diagnosis of ovarian tumors. J Obstet Gynaecol Res. 2013; 39(11):1518-25.
15. Timmerman D, Testa AC, Bourne T, Ameye L, Jurkovic D, Van Holsbeke C, Paladini D, Van Calster B, Vergote I, Van Huffel S, et al. Simple ultrasoundbased rules for the diagnosis of ovarian cancer. Ultrasound Obstet Gynecol. 2008:31(6):681-90.

16. Araujo KG, Jales RM, Pereira PN, Yoshida A, de Angelo Andrade L, Sarian LO, Derchain S. Performance of the IOTA ADNEX model in preoperative discrimination of adnexal masses in a gynecological oncology center. Ultrasound Obstet Gynecol. 2017;49(6):778-83.

17. Zhang F, Zhang ZL. The diagnostic value of transvaginal Sonograph (TVS), color Doppler, and serum tumor marker CA125, CEA, and AFP in ovarian Cancer. Cell Biochem Biophys. 2015;72(2):353-7.

18. Wang J, Gao J, Yao H, Wu Z, Wang M, Qi J. Diagnostic accuracy of serum HE4, CA125 and ROMA in patients with ovarian cancer: a meta-analysis. Tumour Biol. 2014;35(6):6127-38.

19. Hartman CA, Juliato CR, Sarian LO, Toledo MC, Jales RM, Morais SS, Pitta DD, Marussi EF, Derchain S. Ultrasound criteria and CA 125 as predictive variables of ovarian cancer in women with adnexal tumors. Ultrasound Obstet Gynecol. 2012;40(3):360-6.

20. Eagle K, Ledermann JA. Tumor markers in ovarian malignancies. Oncologist. 1997;2(5):324-9.

21. Andersen MR, Goff BA, Lowe KA, Scholler N, Bergan L, Dresher CW, Paley P, Urban N. Combining a symptoms index with CA 125 to improve detection of ovarian cancer. Cancer. 2008;113(3):484-9.

22. Niemi RJ, Saarelainen SK, Luukkaala TH, Maenpaa JU. Reliability of preoperative evaluation of postmenopausal ovarian tumors. J Ovarian Res. 2017;10(1):15.

23. Zheng LE, Qu JY, He F. The diagnosis and pathological value of combined detection of HE4 and CA125 for patients with ovarian cancer. Open Med. 2016;11(1):125-32

24. Koneczny J, Czekierdowski A, Florczak M, Poziemski P, Stachowicz N, Borowski D. The use of sonographic subjective tumor assessment, IOTA logistic regression model 1, IOTA simple rules and GI-RADS system in the preoperative prediction of malignancy in women with adnexal masses. Ginekol Pol. 2017;88(12):647-53.

25. Lycke M, Kristjansdottir B, Sundfeldt K. A multicenter clinical trial validating the performance of HE4, CA125, risk of ovarian malignancy algorithm and risk of malignancy index. Gynecol Oncol. 2018.

26. Goff B. Symptoms associated with ovarian cancer. Clin Obstet Gynecol. 2012;55(1):36-42.

Ready to submit your research? Choose BMC and benefit from

- fast, convenient online submission

- thorough peer review by experienced researchers in your field

- rapid publication on acceptance

- support for research data, including large and complex data types

- gold Open Access which fosters wider collaboration and increased citations

- maximum visibility for your research: over $100 \mathrm{M}$ website views per year

At BMC, research is always in progress.

Learn more biomedcentral.com/submission 